\title{
CASA ECOLOGICAMENTE CORRETA
}

\section{ECOLOGICALLY CORRECT HOUSE}

\begin{abstract}
Gilsimar dos Santos Souza
Graduando em Engenharia Civil, UNIPAC, Brasil, E-mail: gilsimar1001@gmail.com

Luiza de Figueiredo Santos
\end{abstract}

Graduando em Engenharia Civil, UNIPAC, Brasil, E-mail: luizafigueiredo73@gmail.com

Pedro Emílio Amador Salomão

Bacharel, Licenciado, Mestre e Doutor Químico Industrial, UNIPAC, Brasil, E-mail:

pedroemilioamador@yahoo.com.br

Recebido: 06/04/2021 - Aceito: 06/04/2021

\section{Resumo}

A sustentabilidade se faz cada vez mais presente na vida das pessoas, levando o homem a utilizar produtos que não prejudiquem a natureza, e assim minimizar e até sanar os danos causados ao ambiente. A construção sustentável provém do conceito de sustentabilidade o qual engloba três aspectos, o ambiente, a economia e a cultura. Nesse sentido percebe-se que ainda são poucos os empreendimentos sustentáveis em nosso país, sendo fundamental, portanto o desenvolvimento de pesquisas nesta área. Através da elaboração desta proposta de trabalho se tentara identificar os materiais e como a questão da sustentabilidade é utilizada na construção de casas sustentáveis, para tanto serão abordadas questões relacionadas com o significado e as peculiaridades desta forma de empreendimento, quais os materiais ecológicos são empregados atualmente, destacando-se a questão principal a Casa Ecológica, demostrando alguns aspectos de sua construção, sua estrutura básica e o reaproveitamento de matérias no intuito de se preservar a natureza.

Palavras-chave: Sustentabilidade; Casa Ecológica; Reciclagem; Materiais Ecológicos.

\section{Abstract}

Sustainability is becoming more and more present in people's lives, leading man to use products that do not harm nature, and thus minimize and even remedy the damage to the environment. Sustainable construction comes from the concept of sustainability, which encompasses three aspects: the environment, the economy and culture. In this sense, it can be seen that there are still few sustainable ventures in our country, and therefore the development of research in this area is fundamental. Through the elaboration of this work proposal, it was tried to identify the materials and how the issue of sustainability is to use in the construction of sustainable houses, for that matter addressed issues related to the meaning and as peculiarities of this form of enterprise, 
Revista Multidisciplinar do Nordeste Mineiro, v.1, 2021/01

ISSN 2178-6925

which ecological materials are currently used, highlighting the main issue the Casa Ecológica, showing some aspects of its construction, its basic structure and the reuse of places not intended to preserve nature.

Keywords: Sustainability; Ecological house; Recycling; Ecologicos materials 


\section{Introdução}

As casas ecológicas ou como também são chamadas casas verdes são habitações que possuem práticas ecológicas, fazem uso da reciclagem de materiais, ou, proporcionam vantagens econômicas para o meio ambiente bem como produzem menor impacto ambiental. Esse tipo de residência além de menor custo para construção também proporciona menor custo de manutenção, mas deve-se deixar claro que não existe uma casa que seja totalmente ecológica, o que existe na verdade são casas que produzem menor impacto ambiental comparado as residências tradicionais.

Nos dias atuais é enorme a preocupação com a preservação dos recursos naturais e com o futuro do planeta, passou a ter uma maior relevância após a realização da Conferência das Nações Unidas sobre Meio Ambiente e Desenvolvimento no ano de 1992. Iniciou-se assim, uma busca por novas maneiras de desenvolvimento, além de atender as necessidades da população buscam preservar a natureza e assim, não comprometer o planeta para as futuras gerações, surgindo assim, a busca pelo que se chama desenvolvimento sustentável.

Dentre os maiores consumidores dos recursos naturais encontra-se a indústria da construção civil, sendo essa responsável pelo consumo de cerca de $75 \%$ dos recursos naturais que são extraídos (JOHN, 2006), sendo assim, consiste em um dos maiores responsáveis pela degradação ambiental, provocando a necessidade de uma revisão em toda sua cadeia produtiva. Nos países desenvolvidos cada vez mais a construção sustentável tem sido empregada, o que demonstra as exigências desse mercado. Há de se considerar também que a construção sustentável produz aumento da eficiência na utilização dos recursos naturais, uma maior vida útil da infraestrutura, inclusive da dispendiosa infraestrutura pública, como hospitais, escolas, rodovias dentre outros.

A construção civil mesmo destacando-se mundialmente como uma das atividades mais importantes dentro do contexto do progresso econômico e social, esta comporta-se como grande geradora de impactos ambientais, seja através do uso dos materiais retirados da natureza, ou por meio da modificação da paisagem e geração de resíduos.

É importante salientar também que devido às inúmeras variações constantes no clima do planeta, o homem tem procurado soluções ecológicas para a construção, no intuito de minimizar os efeitos que são produzidos devido ao uso irracional dos recursos naturais disponíveis. Tais variações climáticas podem ser vistas 
Revista Multidisciplinar do Nordeste Mineiro, v.1, 2021/01

ISSN 2178-6925

constantemente através dos meios de comunicação, como exemplo: o longo período de estiagem; chuvas torrenciais; ilhas de calor e aumento das emissões de gases do efeito estufa. Dentro deste contexto os cientistas nos últimos anos têm alertado sobre os danos produzidos pelo homem por meio da má utilização dos recursos do planeta, recursos que são essenciais para vida do homem, sendo estes a água e o ar que a cada dia são mais comprometidos.

Nesse sentido a sociedade tem buscado saída através do desenvolvimento de produtos que não prejudiquem o ambiente, estimulando o consumo consciente, reuso de recursos e a reciclagem. É possível tirar proveito da natureza (iluminação e ventilação), racionalizar o consumo da energia, reduzir o uso da água, definir áreas de coleta seletiva de lixo, buscar soluções termo acústicas, sendo que, uma obra sustentável utiliza materiais não prejudiciais ao ambiente (MATTOS, 2008).

De acordo com Abreu (2009) nas grandes cidades do planeta, as construções ecológicas estão mais presentes, os imóveis sustentáveis são uma resposta de engenharia, da arquitetura e da engenhosidade humana para o dilema do uso mais racional de recursos como água e energia. Além disso, efluentes produzidos pelas unidades habitacionais e os resíduos produzidos na construção são corretamente destinados e tratados.

Assim, observa-se a necessidade da preservação ambiental, no sentido de se buscar sua preservação para as gerações futuras, logo como solução possível e fundamental para a garantia da qualidade de vida da sociedade. É importante nessa busca que se desenvolvam alternativas sustentáveis para uso dos recursos naturais, tornando casas, escolas e indústrias ecologicamente corretas, promovendo assim a sustentabilidade.

Sendo assim, minimizar os prejuízos ambientais ocasionados pela construção promove o equilíbrio ecológico, bem como um futuro mais adequado para a humanidade. Cabe salientar acerca dos prejuízos provocados ao meio ambiente o fato de que a degradação ambiental pode evoluir a tal ponto se não se tomar os cuidados devidos com a mesma, que pode ser provocar a extinção do próprio homem com a destruição da natureza.

A sustentabilidade cada vez mais se faz importante e necessária para a humanidade, sendo necessário estudos aprofundados sobre mecanismos de construção, bem como os materiais utilizados. Portanto este trabalho justifica-se devido à importância de pesquisas relacionadas a questão da sustentabilidade, buscando assim contribuir para o desenvolvimento sustentável, em especial, de residências ecológicas. 


\subsection{Objetivos}

\subsubsection{Objetivo Geral}

Verificar e Analisar os materiais, métodos construtivos empregados para construção de casas ecologicamente corretas.

\subsubsection{Objetivos Específicos}

- Analisar o sistema construtivo sustentável;

- Analisar e apresentar os materiais utilizados na construção sustentável;

- Demonstrar a possibilidade da construção de casas com menor impacto ambiental;

- Analisar a utilização dos materiais recicláveis e descartáveis.

\section{Revisão da Literatura}

\subsection{Construção Sustentável}

Conforme apontado por Gonçalves (2006) apud. Prediger (2008), a primeira definição de desenvolvimento sustentável foi feita pelo Brutland Report no ano de 1987, onde este afirmou que desenvolvimento sustentável consiste naquele que atende as necessidades do presente sem vir a comprometer 0 atendimento das futuras gerações.

Segundo os autores Bezerra e Pontes (2002) a sustentabilidade consiste em uma nova consciência, a qual faz com que os homens venham a progredir acerca das questões ecológicas (humana, social, econômica e ambiental), onde por meio desta nova consciência se torna possível conservar e restaurar os recursos naturais que se encontram a nossa disposição no planeta, o que consequentemente beneficia o futuro da humanidade.

A sustentabilidade consiste na forma que as pessoas fazem uso dos recursos naturais disponíveis, com a consciência de que estes podem ser reutilizados, preservando desta maneira a natureza. É fundamental que se compreenda que estes recursos são limitados, logo, deve-se ter o pensamento voltado para o futuro, no que será deixado. Pensando com outras palavras, qual tipo de vida queremos para nós e para o futuro dos que vierem depois (LOPEZ et. al. 2012) 
Revista Multidisciplinar do Nordeste Mineiro, v.1, 2021/01

ISSN 2178-6925

Se tratando da construção sustentável, percebe-se que essa é alicerçada no 
ISSN 2178-6925

conceito de um modelo que permita que a engenharia civil possa enfrentar e propor soluções aos principais problemas ambientais, sem deixar de lado a tecnologia e uma construção que atenda às necessidades de seus ocupantes (IDHEA, 2006).

Ainda segundo IDHEA (2006) a construção sustentável consiste num sistema de construção que busca promover mudanças conscientes, buscando atender as necessidades da edificação, do homem moderno, e assim, cuidar do ambiente, garantindo qualidade de vida agora e futura.

\subsection{Projeto Arquitetônico Sustentável}

Atualmente os edifícios consistem em um dos principais responsáveis pelos impactos na natureza, pois estes consomem mais da metade de toda a energia utilizada nos países desenvolvidos, além disso, são responsáveis pela produção de mais de $50 \%$ dos gases que vem modificando o clima. Neste cenário um projeto de arquitetura sustentável contesta a ideia do edifício como obra de arte e o compreende como parte do habitat vivo, o qual está ligado ao clima, à região e ao planeta (SCHMIDT, 2009).

Ainda conforme Schmidt (2009, p. 24) o projeto arquitetonico sustentável:

Ajuda a difundir maneiras de construir com menor impacto ambiental e maiores ganhos sociais, sem ser inviável economicamente. A elaboração de um projeto de arquitetura na busca por uma maior sustentabilidade deve considerar todo o ciclo de vida da edificação, incluindo seu uso, manutenção, sua reciclagem ou demolição.

De acordo com Nakamura (2006) apud Prediger (2008) o projeto arquitetônico deve ser acomodado no terreno de modo a facilitar os escoamentos e a drenagem, considerar fatores como clima local, construções vizinhas e a influência das mesmas sobre o projeto, os quadrantes de maior radiação, a amplitude térmica local, média de umidade relativa do ar e direção e velocidade dos ventos predominantes.

Existem variadas definições para o termo arquitetura sustentável, contudo, estas possuem objetivos idênticos. De forma geral consiste numa arquitetura que se preocupa não simplesmente com o bem-estar dos moradores, mas com os prejuízos ambientais causados pela construção, identificando quais os materiais e técnicas mais adequadas para cada caso (IDHEA, 2006).

Os autores Corbella e Yannas (2003, p. 17) afirmam que: 
Revista Multidisciplinar do Nordeste Mineiro, v.1, 2021/01

ISSN 2178-6925

de forma a torná-lo parte de um conjunto maior. É a arquitetura que quer criar 
Revista Multidisciplinar do Nordeste Mineiro, v.1, 2021/01

ISSN 2178-6925

prédios objetivando o aumento da qualidade de vida do ser humano no ambiente construído e no seu entorno, integrando as características da vida e do clima locais, consumindo a menor quantidade de energia compatível com o conforto ambiental, para legar um mundo menos poluído para as próximas gerações.

Conforme Simas (2012) projeto arquitetônico sustentável é aquele que possui certificação ambiental. Onde para análise da qualidade do projeto sustentável é necessário a observância de alguns fatores tais como: utilização de placas solares ou painéis fotovoltaicos; utilização da ventilação natural; sistema para reaproveitamento de água; uso de lixos recicláveis; utilização de madeiras do tipo MDF; vasos sanitários eco eficientes dentre outros.

De acordo com Simas (2012) tais dados analisados para se verificar a questão do projeto sustentável, são analisados por Organizações não Governamentais, as quais regulam e certificam as obras sustentáveis com essas características. Essas Organizações também verificam e elaboram relatórios que confirmam se as obras são realmente sustentáveis, entregando as que se enquadram nos critérios analisados 0 selo ou certificado de Sustentabilidade.

\subsection{Tipos de Construção Sustentável}

Toda construção para ser sustentável deve ter características básicas como, fazer uma gestão ambiental da implantação da obra, com mínimo consumo energético e de água durante a execução da obra, utilizar matérias primas que sejam eco eficientes, gerando poucos resíduos e o mínimo de contaminação durante a vida da edificação, integrar-se ao ambiente natural, ser adaptável à necessidades futuras dos usuários e ter um ambiente interior saudável (IDHEA, 2006).

Conforme Fittipaldi (2008) as construções sustentáveis podem ser entendidas como sendo: construídas com eco materiais; construídas com resíduos não processados, reutilização de materiais disponíveis no meio ambiente como garrafas plásticas; construídas com reaproveitamento de materiais oriundos de demolições ou segunda mão; construídas de forma alternativa, utilizam materiais disponíveis no mercado e a essas atribui-se novas funções; construídas de forma natural, utilizando matérias regionais e de baixo custo, indicadas na possibilidade de interação com a natureza e a vegetação.

Para Fernandes Ribeiro (2011) as construções sustentáveis se dividem em dois modelos: construções coordenadas por profissionais da área, que utilizam eco materiais e tecnologias sustentáveis modernas, fabricadas em escala, seguindo normas e padrões 
Revista Multidisciplinar do Nordeste Mineiro, v.1, 2021/01

ISSN 2178-6925

específicos; sistemas de autoconstrução (possuem diversas linhas e 
Revista Multidisciplinar do Nordeste Mineiro, v.1, 2021/01

ISSN 2178-6925

diretrizes), podem ou não ser coordenados por profissionais (autoconstrução), possuem grande criatividade, vontade pessoal do proprietário e responsável pela obra utilizando soluções ecológicas pontuais.

\subsection{Materiais Ecológicos}

Toda construção necessita de matérias para sua execução. Através de uma adequada combinação de métodos e da utilização consciente dos recursos naturais consegue-se um projeto arquitetônico mais sustentável e viável para natureza (BUSSOLOTI, 2011).

Deve-se ter em mente que os materiais ditos ecológicos, devem ser questionados. Sendo necessário verificar se estes produtos correspondem ao que e dito, verificando assim, se estes têm certificações das entidades responsáveis pelas análises dos padrões necessários (SILVA; SILVA, 2011).

Para realização de uma construção sustentável segundo Silva e Silva (2011) os materiais utilizados devem ser de origem próximas do local; que possam ser utilizados até o fim de sua vida útil; recicláveis ou reutilizáveis; não possuir substancias toxicas em sua decomposição; de origem natural e renovável;

Neste sentido percebe-se que o importante não corresponde a forma de produção dos materiais (industrializado, artesanal, manufaturado), estes devem seguir os requisitos citados acima, ou seja, devem essencialmente ser reutilizáveis, ter autonomia energética sem geração de resíduos ou usar energia sustentável.

\subsubsection{Tijolo ecológico ou solo cimento}

O solo cimento conhecido também como tijolo ecológico é um material eco eficiente alternativo muito difundido, sendo definido conforme Sala (2006) como aquele produzido com a mistura de solo e cimento, sendo posteriormente prensados, sendo que esse não necessita a queima, o que contribui com o meio ambiente, pois não se polui o ar. Ainda segundo o autor, em vez da utilização da argamassa comum é utilizada uma cola especial.

O solo cimento consiste num cimento utilizado para a argamassa e para a estrutura, sendo recomendado sua utilização em paredes, revestimentos, pavimentação, fabricação de telhas e tijolos, e outros. É um material homogêneo resultante da mistura de solo, cimento e água. Este não deve possuir na sua composição materiais orgânicos 
Revista Multidisciplinar do Nordeste Mineiro, v.1, 2021/01

ISSN 2178-6925

como adubos e folhas (BUSSOLOTI, 2011). 

2021/01

ISSN 2178-6925

O Tijolo ecológico é desenvolvido através da mistura de solo e cimento prensados; sua fabricação não exige queima em forno à lenha, o que evita desmatamentos e não polui o ar, não lançando resíduos tóxicos no ambiente. Para seu assentamento é utilizada uma cola especial em vez da argamassa, possui dois furos internos, que permitem a colocação da rede hidráulica e elétrica, dispensando o recorte das paredes. O sistema é modular o que beneficia a alvenaria, sendo está uniforme, possibilita a diminuição de percas durante o reboco (SALA, 2006).

\subsubsection{Concreto Reciclável}

Este material pode ser confeccionado com diversas combinações. Na atualidade está disponível no mercado os que utilizam sobras de minérios e asfalto, sendo provenientes de demolições ou entulhos (BUSSOLOTI, 2011).

Para confecção destes, se utiliza um processo simples, o qual consiste na trituração dos resíduos da construção ou demolição num britador, obtendo-se uma mistura semelhante à areia, porém mais grossa (NINNI, 2010).

Por meio da Figura 2 pode ser observado o processo de trituração dos resíduos para confecção do concreto reciclado.

Neste sentido segundo Ninni (2010, p. 21):

O material obtido após a trituração substitui $60 \%$ da areia utilizada normalmente na confecção do concreto tradicional, sendo assim o concreto reciclável possui $40 \%$ de areia tradicional e $60 \%$ de material triturado. Ainda conforme o autor acima, pesquisas revelaram que o mesmo apresentou resistência mais elevada que o concreto tradicional.

\subsubsection{Madeiras Alternativas}

A madeira alternativa é constantemente utilizada na construção, vista como excelente material, disponível em cores, cheiros e durabilidade variada, contudo, sua extração em larga escala promove riscos ambientais. No decorrer do tempo diversas espécies de arvores, bem como florestas inteiras foram extintas para se atender as necessidades do homem. Neste sentido surgiu a preocupação em utilizar madeiras alternativas, proveniente do reflorestamento e devidamente certificadas, sendo de suma importância para as construções sustentáveis (SILVA; SILVA, 2011).

De acordo com Bussoloti (2011) são provenientes do reflorestamento e devidamente certificadas, que durante sua compra é possível verificar a origem e o local 
Revista Multidisciplinar do Nordeste Mineiro, v.1, 2021/01

ISSN 2178-6925

de retirada. Está comprovação e dada por meio de selos concedidos por órgãos competentes e avaliadores. A certificação mais conhecida e o Selo Verde do Forest 

2021/01

ISSN 2178-6925

Stewardship Council (Conselho de Manejo Florestal).

A madeira de Reflorestamento advém de locais que mantém uma área de floresta original ou replantada, onde através do manejo sustentável, produzem novas arvores constantemente. Está atividade prevê a preservação da área florestal ao mesmo tempo em que ocorre a extração de madeira (SILVA; SILVA, 2011).

\subsubsection{Telhas Ecológicas}

Este material possui características mecânicas consideradas melhores que as das telhas tradicionais produzidas, são mais leves, não prejudicam a saúde ou o ambiente. Podem ser confeccionadas com fibras naturais prensadas ou matérias recicladas como Tetra Pak, ou mesmo tubos de creme dental (BUSSOLOTI, 2011).

Ainda segundo Bussoloti (2011) um aspecto importante e que por serem confeccionados por meio de embalagens Tetra Pak, as quais refletem a luz do sol proporcionando um ambiente com condições térmicas melhores.

\subsubsection{Placas Ecológicas}

As placas ecológicas podem ser utilizadas para múltiplos fins e substituem o maderit com enorme vantagem, pois são mais resistentes podendo ser reutilizadas diversas vezes. São produzidas com uma composição plástica, podendo ser utilizadas em áreas externas sem restrição, possuem maior flexibilidade se comparado aos materiais originados da madeira (ECOPRESERVE, 2016)

Além disso possuem uma enorme versatilidade e durabilidade, bem como outras vantagens quando comparadas as madeiras e aglomerados utilizados, proporcionando economia e benefícios ambientais. Podem ser utilizadas de diversas maneiras, como em forros, pisos, divisórias, moveis dentre outros (SILVA; SILVA, 2011).

\subsubsection{Captação da água da chuva}

A água da chuva é destilada e o recolhimento e armazenamento dessa água para uma posterior utilização consistem numa tendência forte e crescente na busca por soluções que visem economizar o uso da água potável tratada. A ideia consiste em não se perder a água da chuva que cai no telhado, pois está caso não seja captada infiltrase na terra, ou segue pelos sistemas de águas pluviais urbanos. Caso esse sistema se sobrecarregue a água não captada acaba por aumentar os casos de alagamentos nos 
Revista Multidisciplinar do Nordeste Mineiro, v.1, 2021/01

centros urbanos (MANOSSO, 2011).

ISSN 2178-6925 
Revista Multidisciplinar do Nordeste Mineiro, v.1, 2021/01

ISSN 2178-6925

A captação de água de chuva consiste numa prática utilizada por inúmeras localidades do mundo e com variados objetivos. Conforme apontado por Sickermann (2000), cerca de $20 \%$ das casas na Alemanha, além de inúmeras empresas possuem cisterna de água filtrada, a qual é utilizada para: descarga de banheiro; lavagem de pisos e carros; irrigação de jardins dentro outras finalidades. Ainda conforme autor acima como exemplo pode ser citada uma lavanderia na cidade de São Paulo que há mais de 30 anos faz uso da água da chuva durante seus processos de lavagem. Existem também diversas pesquisas que tratam do uso das cisternas como alternativo viável e promissor para armazenamento de água em localidades que possuem problema com a escassez hídrica (SILVA, et. al. 2005).

Segundo apontado pelo autor Lee et. al. (2000, apud Campello Netto et al., 2007), os sistemas que fazem a coleta da água da chuva podem ser classificados de acordo com a técnica empregada, podendo neste sentido ser divida em três categorias: coleta em telhado, coleta em superfície e coleta em diversos tipos de barragens. Dentre essas três categorias a que mais se destaca e que tem melhor desempenho para emprego nas casas ecológicas consiste no sistema de coleta em telhado, método simples de captação e armazenamento, constituído, basicamente, de telhado, calha (para transporte da água a partir do telhado) e tanque para armazenamento (RIBEIRO, et. al. 2011)

A água da chuva captada pelos telhados não é potável, pois entra em contato com impurezas por onde passa, contudo, pode ser utilizada em diversas coisas. A chuva ao cair nos telhados é recolhida pelas calhas, passa por um filtro para reter sujeiras como folhas e fica armazenada na cisterna enterrada. Por meio de uma bomba a água é enviada para uma caixa d'água elevada de onde é distribuída para os locais desejados, como vaso sanitário, irrigação, tanque de lavar roupa dentre outros (MANOSSO, 2011).

No meio urbano geralmente a captação da água proveniente das chuvas busca principalmente reduzir a demanda por água tratada; combater enchentes urbanas, as quais são agravadas devido ao excesso de pavimentação e impermeabilização das cidades bem como reduzir o requerimento de galerias pluviais (RIBEIRO, et. al. 2011). Segundo Campello Netto et al. (2007), existem basicamente dois modelos de cisternas utilizados para captação de água do telhado e para captação de água de áreas pavimentadas, sendo que as cisternas construídas com a finalidade de captar a água de chuva possuem como característica o recolhimento de pequena quantidade de água. $O$ tamanho do reservatório a ser utilizado varia segundo a necessidade de consumo, da área do telhado bem como da quantidade de chuva. 


\subsubsection{Energia Solar}

A radiação solar pode ser utilizada diretamente como fonte de energia térmica, para aquecimento de fluidos e ambientes e para geração de potência mecânica ou elétrica. Pode ainda ser convertida diretamente em energia elétrica, por meio de efeitos sobre determinados materiais, entre os quais se destacam o termoelétrico e o fotovoltaico (RIBEIRO, et. al. 2011).

No Brasil, os primeiros projetos apareceram por volta da década de 80 e tiveram como prioridade gerar energia elétrica em locais distantes dos centros de distribuição, como área rural ou comunidades isoladas, com a função de levar água, alimentar sistemas de telecomunicação e sinalização (MORAES, 2007).

Vantagens da energia solar segundo Moraes (2007): Os recursos são inesgotáveis (energia solar); não prejudica a flora e a fauna nem a qualidade do ar e da água; não provoca inundações de grandes áreas; não gera ruídos; a vida útil dos equipamentos é longa (30 anos); instalada diretamente no local de consumo, não requer linhas de transmissão; pode ser incorporada á arquitetura;

No ponto de vista de Adam (2001) apud Michael (2001), esquematicamente existem três modos de transformar a energia solar em edifícios;

a) incorporando dispositivos bioclimáticos ao edifício: jardins de inverno e outros para aquecimento e ventilação de ambientes; b) por meio de painéis coletores solares, que aproveitam a radiação solar como fonte de energia térmica, para aquecimento da água; c) uso do sistema fotovoltaico, que converte energia solar em energia elétrica por meio de painéis de captação conforme Figura 8, geralmente implantados nas coberturas e telhados dos edifícios. Os módulos fotovoltaicos são compostos por células de silício, que têm a propriedade de produzir eletricidade quando expostas à luz; mesmo em dias nublados, os módulos geram energia.

O aproveitamento térmico para aquecimento de fluidos é feito com o uso de coletores ou concentradores solares o que pode ser observado na figura 8 . Os coletores solares são mais usados em aplicações residenciais e comerciais (hotéis, restaurantes, clubes, hospitais etc.) para o aquecimento de água (higiene pessoal e lavagem de utensílios e ambientes). Entre os vários processos de aproveitamento da energia solar, os mais usados atualmente são o aquecimento de água e a geração fotovoltaica de energia elétrica. No Brasil, o primeiro é mais encontrado nas regiões Sul e Sudeste, devido a características climáticas, e o segundo, nas regiões Norte e 

2021/01

ISSN 2178-6925

Nordeste, em comunidades isoladas da rede de energia elétrica (RIBEIRO, et. al. 2011).

\subsection{A Casa Ecológica}

A sociedade atual, cada vez mais opta por construções ecológicas, onde para seu desenvolvimento são utilizados materiais reciclados ou de origem sustentável, aproveitando ao máximo os recursos sem necessidade da industrialização destes. Essas habitações são adaptadas conforme o estilo de vida, possibilitando se ter uma responsabilidade sobre os resíduos gerados, permitindo assim que se administre de forma adequada os recursos ambientais, garantindo assim que estes sejam preservados.

Acerca das casas ecológicas Segundo Silva e Silva (2011, p. 19) diz que: uma casa ecológica tem:

\footnotetext{
Uma casa ecológica tem responsabilidades com o meio ambiente. A principal ideia é utilizar materiais renováveis ou de origens naturais, materiais que utilizem baixo consumo energético e que não emitam substâncias nocivas. Além destes itens, devem ser reduzidos os custos e os impactos ao meio ambiente. Também deve ser observado que a casa deve oferecer conforto aos moradores e ser tão durável quanta uma casa convencional.
}

Esse tipo de habitação consiste num sistema construtivo o qual promove intervenções no meio ambiente, adaptando-o para suas necessidades de uso, produção e consumo humano, sem esgotar os recursos naturais, preservando-os para as gerações futuras (FERNANDES, 2009).

\subsection{Construindo a Casa}

Ao se construir uma casa ecológica, deve-se utilizar recursos e materiais ecológicos, visando não degradar o ambiente. Para sua realização é necessário à contratação de mão de obra especializada, como engenheiros e arquitetos. Tais profissionais buscam reaproveitar os recursos disponíveis, evitando desperdícios da matéria prima e dos recursos naturais.

Segundo Lopez, Califice e Maestri (2012), "para construir as estruturas de uma casa ecológica, são utilizados materiais naturais e sempre de fonte renovável, como plantas, areia, barro, etc.". 
Revista Multidisciplinar do Nordeste Mineiro, v.1, 2021/01

ISSN 2178-6925

quartos, banheiros dentre outros, logo uma casa para ser ecológica deve ser 
ISSN 2178-6925

construída de maneira que todos os ambientes assim como o próprio meio ambiente seja beneficiado.

Segundo Simas (2012) no que tange a parte da alvenaria deste tipo de casa, podem ser utilizados os ecos tijolos (tijolos sustentáveis), os quais são fortes o suficiente para o sustento da casa, são mais caros, contudo são muito eficientes e beneficiam o meio ambiente.

Segundo ressaltado por Lopez, Califice e Maestri (2012, p. 15):

\begin{abstract}
Para a sustentação da casa ou para as demais estruturas, existe o tijolo ecológico. Sua montagem é por encaixe e sua estrutura é formada por uma série de furos em seu interior para que, além da passagem de dutos e sistemas elétricos, possa também servir como sistema térmico, diminuindo a umidade na parede. Este processo ocorre quando 0 ar da parte interna dos tijolos sobe quando é aquecido pelo sol, retornando frio ao seu ponto inicial.
\end{abstract}

Os telhados também podem ser ecológicos, podendo ser construídos através da utilização de fibras de coco verde, os quais não absorvem tanto o calor do sol e mantem a temperatura da casa estabilizada (SIMAS, 2012).

O telhado da casa pode ser construído usando o modelo de telhado verde, o qual se baseia em um jardim plantado sobre o telhado. Sendo utilizadas plantadas gramíneas e que não possuam raízes profundas sobre uma camada impermeável (LOPEZ; CALIFICE; MAESTRI; 2012).

Ainda conforme Lopez, Califice e Maestri (2012, p. 16):

Devido à umidade da terra, o telhado verde melhora o clima da casa, tornandoo mais fresco e úmido. Outro modelo que também pode ser utilizado é o telhado claro, que nada mais é do que um telhado convencional, porém pintado com cores claras, como branco amarelo e azul, pois assim reflete os raios solares proporcionando também um ambiente mais fresco.

A cerca dos telhados Verdes, Lopez, Califice e Maestri (2012) ressaltam que esses podem ser utilizados nas paredes, sendo conhecidos como jardins verticais. Esses podem ser externos ou internos, sendo que na parte externa promovem a redução da emissão de carbono, e na parte interna produzem melhor conforto acústico e térmico.

Paredes que utilizam tal conceito são consideradas como sustentáveis, pois são de forma literal, um jardim sobre a parede, sendo utilizados assim apenas material de origem orgânica e vegetal (VERDER, LOPEZ, CALIFICE e MAESTRI, 2012).

Para as instalações elétricas também pode ser feito o uso de sistemas que preservem o ambiente, através, da instalação de painéis fotovoltaicos, os quais 
ISSN 2178-6925

como um gerador de energia, absorvendo a luz do sol e a convertendo em energia elétrica.

Buscando-se a sustentabilidade e economia para o sistema elétrico também devem ser instaladas lâmpadas mais econômicas, como as lâmpadas fluorescentes ou as LED sendo a mais econômica na atualidade das disponíveis no mercado, o que pode ser observado na TAB. 1.

TABELA 1 - Tabela de consumo das lâmpadas

\begin{tabular}{ccccc}
\hline & LED & Incandescente & Fluorescente \\
\hline Potência (WATTS) & 7 & 40 & 9 \\
Consumo de energia & 0,007 & 0,04 & 0,009 \\
Vida útil (hs) & 100.000 & 1.000 & 12.000 \\
Preço (R\$) & 50,00 & 4,00 & 15,00 \\
\hline
\end{tabular}

Fonte: Simas (2011)

Segundo Simas (2012) para se evitar o desperdício da água, podem ser instaladas torneiras com sensores, sendo estes, sistemas eletrônicos sensíveis a leitura da palma da mão, sendo está uma tecnologia de ponta, adotada para evitar o desperdício de água, pois as torneiras convencionais tendem a gastara água de forma excessiva, pois o fluxo de água só é interrompido quando se fecha a torneira, e nos casos das torneiras com sensores, isto e feito de forma automática, ao se afastar as mão da torneira.

Ainda conforme Simas (2012) podem ser instalados vasos sanitários ecológicos, sendo que estes gastam menos água que os vasos tradicionais, gastando 6 litros, enquanto que os convencionais gastam cerca de 20 litros.

Dentro das casas ecologicamente corretas, até o quesito mobília deve ser levado em conta, sendo possível utilizar itens provindos do reflorestamento ou de materiais reciclados.

Neste sentido Simas (2011, p. 152) diz que:

Todos os itens (camas, sofá, mesa, cadeiras, estantes, guarda-roupas, hacker, prateleiras, armários, criado-mudo, portas), foram feitos com madeira de reflorestamento também conhecida como MDF Usando madeiras de reflorestamento não estará impactando a natureza.

Nas habitações ecológicas a madeira pode ser utilizada em vários locais, como portas, janelas, móveis, divisórias, pisos, vigas e também quando as paredes forem do 
Revista Multidisciplinar do Nordeste Mineiro, v.1, 2021/01

\section{ISSN 2178-6925}

que são usadas para o cultivo de árvores com interesse comercial, a madeira 
ISSN 2178-6925

proveniente destas áreas é chamada madeira de reflorestamento. As árvores plantadas são rápido crescimento como o pinus elliottii e o eucalipto, o que substitui a extração de madeiras nativas evitando o seu consumo e desmatamento (LOPEZ; CALIFICE; MAESTRI; 2012).

Uma construção sustentável não abrange apenas o impacto ambiental, segundo Poujo (2012), este tipo de casa possui o que ele chama de três pilares, sendo estes o pilar ambiental, pilar econômico e pilar social, neste sentido uma casa sustentavel consiste na habitação que atende às necessidades do presente, sem colocar em risco o atendimento das necessidades das futuras gerações.

Também conhecidas como casas ecológicas, essas são projetadas, bem como construídas, buscando-se sempre respeitar o meio ambiente, baseando para tanto em princípios da sustentabilidade ambiental, de forma a se garantir a comodidade e o bemestar de seus ocupantes.

Nesse sentido podem ser observados alguns aspectos comuns existentes nas ditas casas ecológicas, conforme pode ser analisado na TAB 2.

TABELA 2 - Características de uma casa sustentável

\begin{tabular}{|c|c|}
\hline Itens & Característica \\
\hline Sistema elétrico & $\begin{array}{l}\text { Possibilita economia, uso racional, evita } \\
\text { ao máximo o desperdício }\end{array}$ \\
\hline Sistema Hidráulico & $\begin{array}{l}\text { Possibilita economia, uso racional, evita } \\
\text { ao máximo o desperdício }\end{array}$ \\
\hline Sistema de Captação & Captação e utilização da água da chuva \\
\hline Sistema térmico & Diminuição do uso de ar condicionado \\
\hline Madeiras & Possuem origem legal, ou seja, cerificadas \\
\hline Sistema de aquecimento & $\begin{array}{l}\text { Utiliza energia solar, não agredi o } \\
\text { ambiente }\end{array}$ \\
\hline Projeto de Construção & $\begin{array}{c}\text { Considera a iluminação e circulação doar } \\
\text { natural, possibilitando economia elétrica. } \\
\text { Elaborado de forma a não agredir o } \\
\text { ambiente. }\end{array}$ \\
\hline Processo construtivo & $\begin{array}{c}\text { Utilizado de forma a se evitar o } \\
\text { desperdício }\end{array}$ \\
\hline Área Verde & $\begin{array}{c}\text { Uso de jardins com plantio, quando } \\
\text { possível de árvores }\end{array}$ \\
\hline
\end{tabular}


Revista Multidisciplinar do Nordeste Mineiro, v.1, 2021/01

ISSN 2178-6925

Essas habitações são de suma importância para a preservação do meio 
ISSN 2178-6925

ambiente, assim como, o uso adequado dos recursos naturais oferecidos. Deve-se ressaltar que essas possuem vantagens como redução de custos com energia elétrica e água, ambiente residencial agradável, dentre outros.

Assim uma construção ecológica é produzida preocupando-se, quase que única, com a preservação do meio ambiente, deixando este o mais intacto possível e, se possível, reconstituído. O material ecológico ou biodegradável utilizado, as formas de reduzir o consumo de energia, reaproveitamento da água das chuvas, reflorestamento, reciclagem, entre outros, são características que definem a construção como ecológica. (SIMAS, 2012).

\section{Considerações Finais}

Por meio da execução do presente trabalho foi possível compreender que a construção de casas ecológicas beneficia toda a natureza e inclusive o próprio homem, contudo, estas ainda são poucas, fato este que pode estar relacionado ao custo mais elevado em relação às construções convencionais.

No entanto, e importante salientar que os recursos naturais que se encontram disponíveis em nosso planeta não são infinitos e sim escassos, portanto devemos refletir acerca da utilização destes, e repensar o que é mais ideal, se uma economia para execução de uma construção habitacional ou se o que importa mais é a preservação de nossa natureza.

Para finalizar, percebe-se a necessidade da realização de novos estudos mais detalhados sobre a temática da construção civil com a implantação de casas ecológicas, pois verifica-se que essas são essenciais para preservação ambiental se pensando no futuro das próximas gerações futuras. Portanto, fica evidente que uma casa ecológica consiste num projeto ideal de moradia, considerando-se a auto sustentabilidade, bem como garantia de conforto e praticidade. Devido aos problemas que o planeta enfrenta bem como pela enorme necessidade de uma consciência ambiental voltado para a sustentabilidade.

\section{Referências}

ABREU, C. Como ser sustentável? Revista Eletronica - Atitudes Sustentáveis, 2009. Disponível em: <http://www.atitudessustentaveis.com.br/ sustentabilidade /como-sersustentavel> Acesso em 20 de julho de 2020. 
AMBIÊNCIA SOLUÇÕES SUSTENTÁVEIS. Tijolo Ecológico. Disponível em: <http://www.ambiencia.org>. Acesso em: 20 de agosto de 2020.

BEZERRA, M. F. C. PONTES, L.H. (2002) Organizações sustentáveis: você pode construí-las. Apostila explicativa publicada em setembro de 2002.

BUSSOLOTI, Fernando. Como funcionam as construções sustentáveis. Revista Eletrônica. Como Tudo Funciona, 2011. Disponível em:<.http://ambiente.hsw. uol.com.br/construcoes-ecologicas3.htm> em 03 de setembro de 2020.

CAMPELLO NETTO, M.S.C.; COSTA, M.R., CABRAL, J.J.S.P. (2007) Capítulo 10 Manejo Integrado de Água no Semiárido Brasileiro. O uso sustentável dos recursos hídricos em regiões semiáridas. Editora Universitária, Recife - PE, 1 ed., p. 473-501, 2007.

CORBELLA, Oscar; YANNAS, Simos. Em busca de uma arquitetura sustentável para os trópicos: conforto ambiental. Rio de Janeiro: Revan, 2003.

ECOPRESERVE. Placas e chapas ecológicas. 2016. Disponível em: <http://ww w.ecopreserve.com.br/chapas.php>. Acessado em 10 de setembro de 2020.

FERNANDES, André Luiz Genelhú. Sustentabilidade das Construções Construções para um futuro melhor - Reaproveitamento da água [monografia]. Universidade Federal de Minas Gerais - UFMG. Belo Horizonte, Junho de 2009.

FERNANDES RIBEIRO, Amanda Fernandes, et. al. Materiais alternativos para construção civil Projeto da casa ecológica. Trabalho acadêmico [artigo]. $26 \mathrm{p}$. Colegiado de Engenharia Civil da Faculdade do Sul da Bahia. Teixeira de Freitas - BA, 2011.

FITTIPALDI, Mônica. Habitação social e Arquitetura Sustentável em Ilhéus/BA [Tese Mestrado]. Universidade Estadual de Santa Cruz. ILHÉUS - Bahia, 2008.

IDHEA - Instituto para o Desenvolvimento da Habitação Ecológica. Materiais ecológicos e tecnologias sustentáveis para arquitetura e construção civil: conceito e teoria. Apostila n. 2 do curso Materiais Ecológicos e Tecnologias Sustentáveis. São Paulo, 2006.

IDHEA - Instituto para o Desenvolvimento da Habitação Ecológica. Nove Passos para a Obra Sustentável. São Paulo, 2006. Apostila do curso Materiais Ecológicos e Tecnologias Sustentáveis. São Paulo, 2006. 
Revista Multidisciplinar do Nordeste Mineiro, v.1, 2021/01

\section{ISSN 2178-6925}

metodologia de pesquisa e desenvolvimento. São Paulo, 2000, 102 p. Tese (Livre 
ISSN 2178-6925

docência). Departamento de Engenharia de Construção Civil, Escola Politécnica da Universidade de São Paulo.

LOPEZ, Caroline; CALIFICE, Karina; MAESTRI, Paula. Casa ecológica: Uma moradia sustentável. Colégio Mãe de Deus. Revista Eletrônica. Volume 3, página 9. Setembro de 2012.

MANOSSO, Radamés. Captação de Água da Chuva. Revista eletrônica ECOnservar. 2011. Disponível em: < www.radames.manosso.nom.br/ambiental >. Acessado em 05 de agosto de 2020.

MATTOS, M. L., Faça a sua parte!. Revista Casa e Construção, n.37, p.60-63, (s/d). São Paulo, 2008.

MICHAEL, R., O Conceito de Sustentabilidade Aplicado a uma Edificação na Cidade de ljuí-RS. 2001. Trabalho de Conclusão de Curso (Graduação em Engenharia Civil) - Universidade Regional do Noroeste do Estado do Rio Grande do Sul, ljuí, 2001.

MORAES, M., À Luz do Sol. Revista Arquitetura e construção. São Paulo, Ano 23, n.9, p.143, set./2007.

NINNI, Karina. Concreto reciclado custa 30\% menos. Estadão, 27 de julho de 2010. Disponível em: <http://sustentabilidade.estadao.com.br/noticias/geral, concretoreciclado-custa-30-menos,586746>. Acessado em 10 de setembro de 2020.

PEDIGRER, P. W., Avaliação do Grau de Sustentabilidade de um Condomínio Residencial- Estudo de Caso. 2008. Trabalho de Conclusão de Curso (Graduação em Engenharia Civil) - Universidade Regional do Noroeste do Estado do Rio Grande do Sul, ljuí, 2008.

POUJO, Carin Kutchma. Acessibilidade e Construção Sustentável: Um Paradigma na Habitação de Interesse Social. Universidade Federal do Rio de Janeiro, Rio de Janeiro, 2012.

SALA, L. G. Proposta de Habitação Sustentável para Estudantes Universitários [Monografia] (Graduação em Engenharia Civil). Universidade Regional do Noroeste do Estado do Rio Grande do Sul/UNIJUI. 2006.

SILVA, Dieni Carlos Eduardo Moreira; SILVA, Felix Trindade da. Casas Ecológicas [monografia]. Universidade Anhebi Morumbi. São Paulo, 2011. 
Revista Multidisciplinar do Nordeste Mineiro, v.1, 2021/01

ISSN 2178-6925

SILVA, L.; ALMEIDA, H. A.; COSTA FILHO, J. F. (2005). Captação de Águas de Chuva na Zona Rural: Uma Alternativa para a Convivência no o Semiárido 
Revista Multidisciplinar do Nordeste Mineiro, v.1, 2021/01

ISSN 2178-6925

Nordestino. V Simpósio Brasileiro de Captação e Manejo de Água de Chuva. Petrolina -PE, 2005.

SIMAS, Leonardo Santa Luzia. Construção sustentável - uma nova modalidade para administrar os recursos naturais para a construção de uma casa ecológica. Fundação Visconde de Cairu, 2012. Disponível em: <http://www.cairu.br/revista/arquivos/artigos/2012_2/11_Construcoes_Sustentaveis_Le onardo_Sim as_140_162.pdf>. Acessado em 10 de setembro de 2020.

SCHMIDT, Franciele Taise Manica. Aplicação do conceito de sustentabilidade em uma Edificação residencial unifamiliar - estudo de caso. Trabalho de Conclusão de Curso [monografia]. UNIJUÍ - Universidade Regional do Noroeste Do Estado do Rio Grande do Sul. ljuí, novembro de 2009. 